\title{
RADIOLOGICAL AGE ESTIMATION FROM FUSION AT XIPHI- STERNAL JOINT OF LIVING PERSONS THROUGH CT IMAGES OF THORACIC REGION
}

\author{
Herath L.H.M.I.M.', Senanayake G. ${ }^{2}$ \& Jeyasugiththan J. ${ }^{3}$ \\ 'Department of Radiography \& Radiotherapy, Faculty of Allied Health Sciences, ${ }^{2}$ Department of \\ Pre-clinical, Faculty of Medicine, General Sir John Kotelawala Defense University, Sri Lanka. \\ ${ }^{3}$ Department of Nuclear Science, Faculty of Science, University of Colombo, Sri Lanka \\ Corresponding Author: Herath L.H.M.I.M. \\ Email: indeewariherath23@gmail.com \\ https: / / orcid.org / 0000-0002-5202-1052
}

\begin{abstract}
Determination of age is really important and sometimes it is a difficult task in medicolegal practices. Aim of this study was to confirm whether the status of the fusion at xiphisternal joint can be used to estimate the age. Total of 275 , who underwent computed tomography (CT) thoracic examination, were selected as the study sample. RadiAnt Digital Imaging and Communications in Medicine (DICOM) viewer was used to observe the fusion state. There was a negative correlation between fusion category and age in males $(r=-0.325, p<0.001)$, no significant correlation in females $(r=0.094$, $\mathrm{p}=0.346)$ and, a negatively significant correlation $(\mathrm{r}=-0.165, \mathrm{p}=0.006)$ in both sexes. There was a statistically significant difference in age between different fusion categories, $\chi^{2}(2)=63.61, p<0.001$ in males, $\chi^{2}(2)=31.98, p<0.001$ in females and, $\chi^{2}=97.76, p<0.001$ in both sexes. There was a strong negative correlation between non-fusion age and distance of joint space in males $(r=-0.479, \mathrm{p}=0.006)$, in females $(\mathrm{r}=-0.963, \mathrm{p}<0.001)$ and, in both sexes $(\mathrm{r}=-0.758, \mathrm{p}<0.001)$.
\end{abstract}

Keywords: age estimation, fusion state, xiphisternal joint 


\section{INTRODUCTION}

One important parameter which helps for the identification of an individual is age whether the person is alive, dead or human remains. Every person whether dead or alive has right to be identified for several reasons. Living person may require age estimation when birth certificate is not available or records are doubtful, to determine the age in criminal liability, to assess whether the child has attained the age of criminal responsibility such as rape, kidnapping, employment, premature births, adoption, illegal immigration etc. and in cases of illegal marriages. Dead person may require age estimation during disaster victim identification such as fires, crashes, accidents, homicides etc. and aborted fetal age determination.

Determination of age is really important and sometimes it is a difficult task in medico-legal practices. Especially in the setting of a crime investigation or a mass disaster, it is difficult for investigators to determine the age of unknown human bodies since there is a large number of possible matches. Using various methods of estimating age, investigators estimate the age and try to identify the unknown body.

As mentioned above, not only in the criminal cases but also in the civil cases age determination plays a vital role. Most of the developing countries don't have a perfect way to record age in past and also most of the old age people don't have their birth certificate and national identity card (NIC) with them and even don't remember their age. According to the age of a person various government agencies give benefits like employment, pension, medical reimbursement and concession. In some countries railways authority gives concession of $40 \%$ to male senior citizens and $50 \%$ to female senior citizens where a senior citizen is considered as age more than 60 years ${ }^{1}$.
In general, the method used for age estimation is not changed though the person is living or dead. It is carried out using methods relying on macroscopic morphological features, radiology, microscopic features, chemical and molecular biology and radiocarbon (14C) analysis $^{2}$.

Radiological assessment of age is really benefited in forensic anthropological cases like in mass graves and mass disasters where the soft tissue removal is not feasible or where a quick age determination is required as the initial step of person identification. Several of the above mentioned morphological methods have been studied using radiology.

When radiology is used to determine the age with the help of bones or joints, CT examinations play a vital role since CT scanners produce the detailed images of bones with high-resolution. These images can be used to evaluate the joint spaces. Since the modern cross-sectional imaging technology is incorporated into the CT machines, images generated are free of superimposition from other overlying structures. Usually, CT scanners generate images in the axial plane, but, modern scanners allow this volume of data to be reformatted in various planes such as sagittal and coronal. This volume of data can also be used to form volumetric (3D) representations of structures. Another importance of doing CT examination is because of high resolution data acquired in a single breath hold since it has a very short scan time ${ }^{3}$.

Some literatures have shown that the sternum is also used as an important tool to determine the age especially in middle aged and old aged persons. When the sternum is used, the status of its fusions between manubrium and the body of the sternum and between xiphoid process and body of the sternum is considered and in comparison radiological examination of 
sternum is easy and applicable to both dead as well as living ${ }^{4}$.

Several research studies say that the fusion at xiphisternal joint can be used as an important tool to determine the age of an unknown person. According to the results given in those studies, it was noticed that there is a discrepancy in age of fusion at xiphisternal joint. This discrepancy motivated to do the present study. Further, there was no any published literature done on age determination using fusion at xiphisternal joint for Sri Lankan population. The objective of the present study was to confirm whether the status of the fusion at xiphisternal joint can be used as a tool to estimate the age.

\section{MATERIALS AND METHOD}

Present study was carried out on patients from both sexes in different ages who underwent $\mathrm{CT}$ thoracic examination done using TOSHIBA Alexion 16 slice Multi Detector Computed Tomography (MDCT) machine at Sri Jayewardenepura Hospital. Convenient sampling method was used to select the subjects for the study and data were collected through machine storage at the hospital with no inconvenience to the hospital setup. The study sample consisted of all the patients, who were not in the exclusion criteria, came for CT thoracic examination during the period of data collection from April 2018 to August 2018. Therefore 275 patients including 172 males (from 17 years of age to 86 years of age) and 103 females (from 19 years of age to 87 years of age) were selected after assessing against the exclusion criteria of having a disease or a damage in respect to anterior chest wall and/or the sternum. The ethical clearance for the study was taken from the Ethical Review Committee (ERC) of Faculty of Medicine, General Sir John Kotelawala Defence University and the permission was granted from the hospital after giving the ethical clearance certificate to the hospital. Axial images of thoracic region which were taken for each patient who underwent $\mathrm{CT}$ thoracic examination were copied into digital versatile discs (DVDs) monthly using storage data in the CT machine at Sri Jayewardenepura Hospital. Using RadiAnt DICOM viewer installed into the personal computer, the axial images were observed for any exclusion criteria with the help of a consultant radiologist. The copied data which showed any disease or damage to anterior chest wall and/or to the sternum were discarded and not included to the study sample. Then a 3D image of thoracic region was created for each study participant using collected axial images by '3D Volume Rendering' tool. Then the unwanted structures surrounded to the sternum were selected and deleted using 'Scalpel' tool available in the viewer for easy viewing of sternum. The image was rotated by '3D Rotate' tool to delete the structures which were posterior to the sternum. Then the xiphisternal joint was observed by rotating the image using ' $3 \mathrm{D}$ Rotate' tool and the state of the fusion of xiphoid process with the body of the sternum was decided by the same radiologist on zoomed in image. State of the fusion was categorized as partial fusion (partially fused), complete fusion (completely fused) and absence of fusion (separate/not fused) and recorded with the age and sex of each study participant in an Excel sheet. The average distance between body of the sternum and the xiphoid process was taken and recorded in millimeters $(\mathrm{mm})$ using three distances measured at three different points of the joint space for the study participants who had unfused xiphoid process. All analysis was completed using IBM Statistical Package for the Social Sciences (SPSS) 20 software for Windows. An alpha level of 0.05 was used for significance in all statistic testing. Fusion state was ranked as 'partial fusion $=1$ ', 'complete fusion $=2$ ' and 'absence of fusion $=3$ ' for easy analysis. All study cases were divided into age 
groups as $15-24,25-34,35-44,45-54,55-$ 64, 65-74, 75-84, and 85-94. The association of fusion ranks with the age and the association between non-fusion age and the distance of joint space were examined using Spearman correlation since data were not in the normal distribution. The $\mathrm{K}$ independent sample Kruskal-Wallis $\mathrm{H}$ test was used to examine whether there is a difference in ages which show each fusion state. Curve estimation was used to find the most fitted curve which show the relation between the joint space distance and the non-fusion age and then the non-linear regression was used to create a model to estimate the age of a person who is having an unfused xiphoid process. All analysis was done for males and females separately. Finally, results were compared with the results of similar literatures.

\section{RESULTS}

Table 1: Distribution of cases according to the age

\begin{tabular}{|l|l|l|l|l|l|}
\hline \multirow{2}{*}{$\begin{array}{l}\text { Age } \\
\text { Groups } \\
(\text { Yrs. })\end{array}$} & \multicolumn{4}{|c|}{ Sex } & \multirow{2}{*}{$\begin{array}{l}\text { Total (\%) } \\
\text { n=275 }\end{array}$} \\
\cline { 2 - 5 } & $\mathbf{N}$ & Male & $\mathbf{N}$ & Female & \\
\hline $15-24$ & 4 & 2.32 & 1 & 0.97 & $5(1.81)$ \\
\hline $25-34$ & 12 & 6.97 & 2 & 1.94 & $14(5.09)$ \\
\hline $35-44$ & 20 & 11.62 & 6 & 5.82 & $26(9.45)$ \\
\hline $45-54$ & 19 & 11.04 & 16 & 15.53 & $35(12.72)$ \\
\hline $55-64$ & 34 & 19.76 & 25 & 24.27 & $59(21.45)$ \\
\hline $65-74$ & 48 & 27.9 & 31 & 30.09 & $79(28.72)$ \\
\hline $75-84$ & 33 & 19.18 & 18 & 17.47 & $51(18.54)$ \\
$85-94$ & 2 & 1.16 & 4 & 3.88 & $6(2.18)$ \\
\hline
\end{tabular}

Table 2: Relation between fusions at xiphisternum according to the age

\begin{tabular}{|c|c|c|c|c|c|c|}
\hline \multirow{3}{*}{$\begin{array}{l}\text { Age } \\
\text { Group } \\
\text { (Yrs.) }\end{array}$} & \multicolumn{6}{|c|}{ Sex } \\
\hline & \multicolumn{3}{|c|}{ Male } & \multicolumn{3}{|c|}{ Female } \\
\hline & $\begin{array}{l}\text { Not-fused } \\
(\%)\end{array}$ & $\begin{array}{l}\text { Partially } \\
\text { Fused } \\
(\%)\end{array}$ & $\begin{array}{l}\text { Completely } \\
\text { Fused (\%) }\end{array}$ & $\begin{array}{l}\text { Not-fused } \\
(\%)\end{array}$ & $\begin{array}{l}\text { Partially } \\
\text { Fused (\%) }\end{array}$ & $\begin{array}{l}\text { Completely } \\
\text { Fused }(\%)\end{array}$ \\
\hline $15-24$ & $3(75.0)$ & $0(0.0)$ & $1(25.0)$ & $1(100.0)$ & $0(0.0)$ & $0(0.0)$ \\
\hline $25-34$ & $11(91.6)$ & $0(0.0)$ & $1(8.3)$ & $2(100.0)$ & $0(0.0)$ & $0(0.0)$ \\
\hline $35-44$ & $15(75.0)$ & $5(25.0)$ & $0(0.0)$ & $5(83.3)$ & $0(0.0)$ & $1(16.6)$ \\
\hline $45-54$ & $0(0.0)$ & $7(36.8)$ & $12(63.1)$ & $2(12.5)$ & $13(81.2)$ & $1(6.2)$ \\
\hline $55-64$ & $0(0.0)$ & $0(0.0)$ & $34(100.0)$ & $0(0.0)$ & $8(32.0)$ & $17(68.0)$ \\
\hline $65-74$ & $1(2.0)$ & $1(2.0)$ & $46(95.8)$ & $2(6.4)$ & $0(0.0)$ & $29(93.5)$ \\
\hline $75-84$ & $1(3.0)$ & $1(3.0)$ & $31(93.9)$ & $1(5.5)$ & $2(11.1)$ & $15(83.3)$ \\
\hline $\begin{array}{l}85-94 \\
\text { Total }\end{array}$ & $\begin{array}{l}0(0.0) \\
31(18.0)\end{array}$ & $\begin{array}{l}0(0.0) \\
14(8.1)\end{array}$ & $\begin{array}{l}2(100.0) \\
127(73.8)\end{array}$ & $\begin{array}{l}1(25.0) \\
14(13.6)\end{array}$ & $\begin{array}{l}0(0.0) \\
23(22.3)\end{array}$ & $\begin{array}{l}3(75.0) \\
66(64.0)\end{array}$ \\
\hline
\end{tabular}




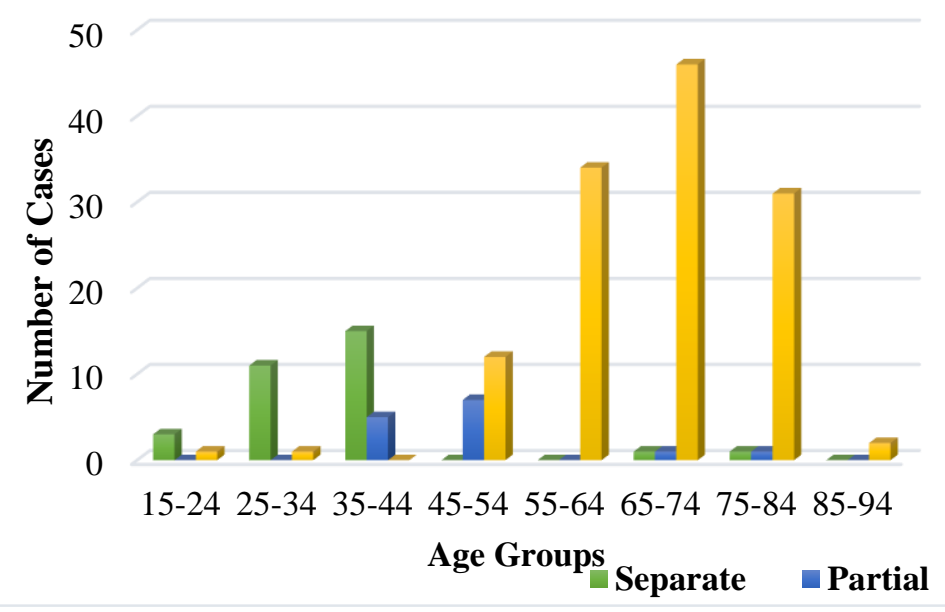

Fig. 1: Relation between fusions of xiphoid with sternal body according to the age group in male

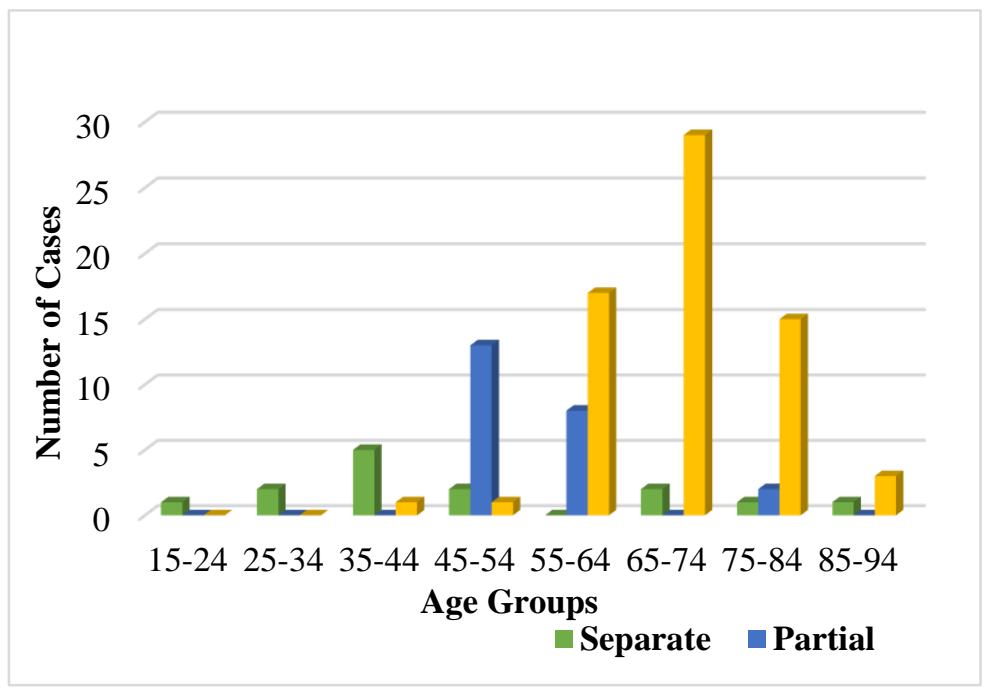

Fig. 2: Relation between fusions of xiphoid with sternal body according to the age group in females

Table 3: Correlation between fusion state and age with and without stratification by sex

\begin{tabular}{|l|l|l|l|}
\hline Age & Sex & Spearman $\boldsymbol{r}$ & $\boldsymbol{p}$ value \\
\hline \multirow{3}{*}{ All } & Male & -0.325 & $<0.001$ \\
\cline { 2 - 4 } & Female & 0.094 & 0.346 \\
\cline { 2 - 4 } & Both & -0.165 & 0.006 \\
\hline
\end{tabular}


Table 4: Relation between fusion ranks and age

\begin{tabular}{|l|l|l|l|l|l|l|}
\hline Age & Sex & Fusion Rank & $\begin{array}{l}\text { Number } \\
\text { of Cases }\end{array}$ & $\begin{array}{l}\text { Mean } \\
\text { Rank }\end{array}$ & \multicolumn{2}{|l|}{$\begin{array}{l}\text { Kruskal-Wallis test } \\
\text { df= 2 value }\end{array}$} \\
\hline \multirow{4}{*}{ All } & Male & Non-fusion & 31 & 29.39 & 63.61 & $<0.001$ \\
\cline { 2 - 7 } & & Partial fusion & 14 & 52.14 & & \\
\cline { 2 - 7 } & & Complete fusion & 127 & 104.23 & & \\
\cline { 2 - 7 } & Female & Non-fusion & 14 & 27.29 & 31.98 & $<0.001$ \\
\hline & Partial fusion & 23 & 31.39 & & \\
\cline { 2 - 7 } & & Complete fusion & 66 & 64.42 & & \\
\cline { 2 - 7 } & Both & Non-fusion & 45 & 53.84 & 92.76 & $<0.001$ \\
\cline { 2 - 7 } & & Partial fusion & 37 & 86.26 & & \\
\cline { 2 - 7 } & & Complete fusion & 193 & 167.54 & & \\
\hline
\end{tabular}

Table 5: Correlations of non-fusion age with distance of joint space between xiphoid process and body of the sternum for all age groups with and without stratification by sex

\begin{tabular}{|l|l|l|c|}
\hline Age & Sex & Spearman $\boldsymbol{r}$ & $\boldsymbol{p}$ value \\
\hline \multirow{3}{*}{ All } & Male & -0.479 & 0.006 \\
\cline { 2 - 4 } & Female & -0.963 & $<0.001$ \\
\cline { 2 - 4 } & Both & -0.758 & $<0.001$ \\
\hline
\end{tabular}

\section{DISCUSSION}

The model equation which can be used to estimate the non-fusion age of a male person when the distance at xiphisternal joint space is known was revealed as follows;

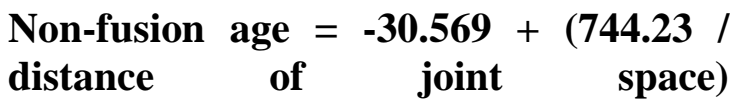

The model equation which can be used to estimate the non-fusion age of a female person when the distance at xiphisternal joint space is known was revealed as follows;

$$
\begin{array}{ll}
\text { Ln }(\text { non-fusion age }) & =\underset{\text { joint }}{1.957} \\
\text { distance of } & +(17.994 / \\
\text { space })
\end{array}
$$

The present study measured the xiphoid process fusion from CT scans and, to best of our knowledge, is the first study of its kind to examine developmental trends in xiphoid process with the age in Sri Lanka. The results show no partial or complete fusion before 20 years of age in any sex. The early fusion was reported in the age of 20 years in males. This proves the statement given by Saladin \& Kenneth (2010) where the xiphoid process may become joined to the body before the age of thirty ${ }^{5}$. This early fusion age revealed from the present study differs from the results given in some similar studies. One study was carried out on 192 living persons to study the radiological age estimation from xiphisternal joint and they concluded that the earliest age of fusion of xiphoid process with the body of the sternum was 36 years 
in males and 35 years in females ${ }^{6}$. The other study was carried out on 116 cases of age above 10 years including both sexes to determine the age by gross and radiological aspect of sternum and it revealed that the earliest age of complete fusion of xiphoid process was 31 years $^{7}$.

But when the early fusion age of 20 years in the present study compares with the results given by the study conducted to estimate the age from sternum for age group 25 years onwards, it was revealed that there is a similarity with the earliest age of fusion of 26 years in both males and females which showed in that study ${ }^{1}$.

Further, another similarity was found from the study done on time of fusion of mesosternum with manubrium and xiphoid process $^{8}$. According to their results, 03 male cases were recorded with complete fusion of xiphisternum within the age group of 18-20 years. Moreover, a study done in Punjab on time of fusion of the human mesosternum with manubrium \& xiphoid process in sterna obtained from 772 male and 208 female subjects revealed that the xiphoid process did not fuse with the body of the sternum in males below 18 years and female below 21 years 9 .

As said by some authors, results of the present study also show that ossification of xiphisternal joint delays up to late adulthood since the late fusion was reported in the age of 84 years in males and 86 years in females ${ }^{10}$. Similar result was found in another literature as they mention that the late fusion was found at 81 years in males and 80 years in females ${ }^{1}$. Further, this result of late fusion age revealed from the present study is confirmed by the result given in another similar literature ${ }^{8}$. As this study says 09 male cases were recorded with absence of fusion within the age group of 61 years and above. This observation on late fusion age of the present study is however in contradiction to the result given in a similar study done to estimate the age using fusion at xiphisternum since they concluded that their observation on latest age of fusion was 59 years in males and 56 years in females ${ }^{6}$. Further, the result on late fusion age of present study proves the statement given by Saladin \& Kenneth (2010) where the xiphoid process sometimes remains ununited in old age ${ }^{5}$.

According to the observations of present study, it was found that the majority of both males and females showed complete fusion as 127 cases $(73.8 \%)$ in males and 66 cases $(64 \%)$ in females. More than one third of them showed the complete fusion in the age group of 65-74 years in both sexes as 46 cases $(36.2 \%)$ in males and 29 cases $(44 \%)$ in females. This means the higher probability of occurrence of complete fusion (36.22\% in males \& $44 \%$ in females) was found in the age group of 65-74 years. As shown in the present study, average age of complete fusion in males is 65.70 years and in females is 68.83 years. When compare this result with the similar literatures, one study showed that it was 50.04 years in males and 46.42 years in females while another study said that it was 54.33 years in males and 57.86 years in females $^{6,1}$. This discrepancy proves the statement given by Saladin \& Kenneth (2010) where the union of xiphoid process with the body of the sternum occurs more frequently after forty ${ }^{5}$.

According to the results, no case has been noted as 'partially fused' up to the age group of 35-44 years in males and 45-54 years in females. When see the result given in a study done on age determination using gross and radiological assessment of sternum, it showed that partial fusion started from the age group of 31-40 years in both males and females ${ }^{7}$.

According to the observations in the present study, $6.45 \%$ were reported as not-fused and $64.28 \%$ were reported as partiallyfused in males while $42.85 \%$ were reported as not-fused and $100 \%$ were reported as 
partially-fused in females after 44 years of age. Therefore, present study agrees with the statement given in the study done in India 2011 where the forensic experts should be cautious when estimate the age of persons above 40 years on the basis of fusion of xiphisternal joint ${ }^{6}$.

\section{CONCLUSION}

In conclusion, present study would like to say that fusion state alone has been shown to be insufficient to estimate the age. The age of an unknown person who is having a not-fused xiphisternum can be estimated using proposed regression models and additional measurements including density, thickness, length etc. of the sternal body and xiphoid process from CT scans would permit to modify the proposed regression models for absence of fusion. These additional measurements will be helpful to develop more accurate regression models to determine the age of an unknown person having completely fused and partially fused xiphoid process. The use of a clear fusion ranking system, such as the one used here can help clarify some of the inconsistencies in published research findings to date. This research provides a baseline for understanding typical xiphoid process fusion with possible implications for the field of forensic medicine, medico-legal practice and anatomy.

\section{ACKNOWLEDGEMENT}

We would like to express our gratitude to the Director, in-charge radiographer and all the other staff of the radiology department at Sri Jayewardenepura Hospital.

\section{REFERENCES}

1. Chopra, M., Singh, H., Kohil, K. \& Aggarwal, O. P., 2014. Age Estimation from Sternum for Age Group 25 Years Onwards. J Indian Acad Forensic Med, 36(3), pp. 270-272.

2. Villa, C. \& Lynnerup, N., 2014. Age estimation of skeletal remains. Research and Reports in Forensic Medical Science, (4), pp. 3-9.

3. Gakhar, G. K., Gupta, V., Jasuja, O. P. \& Khandelwal, N., 2014. Determining the Ossification Status of Sternal End of the Clavicle using. Journal of Forensic Research, 5(2), pp. 1-6.

4. Silajiya, D. A. et al., 2013. Radiological Age Estimation from Sternum. National Journal of Integrated Research in Medicine, 4(4), pp. 108-114.

5. Saladin \& Kenneth, S., 2010. Anatomy and Physiology: The Unity of Form and Function. Fifth Edition ed. New York: McGraw-Hill.

6. Garg, A., Goyal, N. \& Gorea, R. K., 2011. Radiological Age Estimation from XiphiSternal Joint in Living Person. J Indian Acad Forensic Med, 33(1), pp. 27-29.

7. Tailor, C. I. et al., 2013. Age Determination by Gross and Radiological Aspect of Sternum. J Indian Acad Forensic Med, 35(1), pp. 21-25.

8. Singh, D., Inderjit \& Sanjeev, 1994. Time of fusion of mesosternum with manubrium and xiphoid process. Journal of the Anatomical Society of India, 43(2), pp. 125-135.

9. Jit, I. \& Bukshi, 1986. Time of the human mesosternum with manubrium and xiphoid process. Indian Journal of Medical Research, Volume 83, pp. 322-331.

10. Neal, M. L., Dwornik, J. J., Ganey, T. M. \& Ogden, J. A., 1998. Postnatal Development of the Human Sternum. J Pediatr Orthop, 18(3), pp. 398-405. 